\author{
Mateusz MUCHA ${ }^{1}$
}

\title{
PROTOTYPOWY SYSTEM ROZPOZNAWANIA TABLIC REJESTRACYJNYCH Z WYKORZYSTANIEM SIECI NEURONOWYCH
}

\begin{abstract}
W artykule przedstawiono prototypowy system rozpoznawania tablic rejestracyjnych oparty o urządzenie Raspberry PI 2, zaprojektowany jako niskobudżetowa alternatywa dla komercyjnych rozwiązań. Praca opisuje poszczególne komponenty sprzętowe, aplikację sterującą rozpoznawaniem tekstu oraz przeprowadzone badania, pokazujące poprawność odczytu. Opisany został zastosowany algorytm, a także samo rozpoznawanie tekstu oparte o sztuczne sieci neuronowe.
\end{abstract}

Słowa kluczowe: OCR, OpenCV, Python, Raspberry PI 2, Sieci neuronowe

\section{Wprowadzenie}

Obecnie wiele uwagi przykłada się do kontroli wjazdu. Powstają obiekty o zamkniętym dostępie, takie jak osiedla mieszkaniowe, do których dostęp ma jedynie wybrana grupa pojazdów. Ograniczeniem dostępu zazwyczaj jest brama wjazdowa lub szlaban. Sterowanie nimi przez jedną osobę nie jest kłopotliwe, jednak w przypadku wielu osób może być już problemem. Można zastosować urządzenie, które w sposób automatyczny rozpozna pojazd za pomocą jego identyfikatora, którym jest tablica rejestracyjna, a następnie - w przypadku posiadania odpowiednich uprawnień - udzieli mu dostępu.

Prototypowy system rozpoznawania tablic rejestracyjnych jest propozycją takiego urządzenia. Może ono rozpoznać tablicę rejestracyjną na podstawie wykonanego zdjęcia, a dzięki wbudowanej bazie danych zezwolić, na wjazd pojazdu lub go odmówić.

Prototypowe rozwiązanie zostało zaimplementowane na platformie sprzętowej Raspberry Pi 2 wyposażonej w procesor ARM Cortex-A7 CPU z czterema rdzeniami taktowanymi częstotliwością $900 \mathrm{MHz}$ [1]. Pozwala to na wykonywanie zaawansowanych obliczeń. Urządzenie ma do dyspozycji $1 \mathrm{~GB}$ pamięci RAM. Dane przechowywane są na karcie micro SD, której minimalna prędkość zapisu wynosi $10 \mathrm{MB} / \mathrm{s}$. Za część programową odpowiada system Linux.

\footnotetext{
${ }^{1}$ Mateusz Mucha, Krasne 10A, 36-007 Krasne, tel. 501252243, mateusz.mucha@wp.pl
} 
Do urządzenia została podłączona kamera o rozdzielczości 5MPx, która w momencie wykrycia tablicy rejestracyjnej, robi jej zdjęcie [2]. Obecność pojazdów przed urządzeniem identyfikuje czujnik ultradźwiękowy HC-SR04, którego zadaniem jest stwierdzenie czy przed kamerą znajduje się tablica, czy też nie. Jest również możliwa detekcja za pomocą samej kamery, jednak w takim przypadku obciążenie urządzenia Raspberry Pi 2 staje się dużo większe. Spada wydajność przetwarzania danych. Urządzenie posiada także kartę sieciową, za pomocą której możliwa jest komunikacja w celu dodania lub usunięcia tablicy rejestracyjnej. Potencjalny użytkownik informowany jest o aktualnym stanie systemu za pomocą wbudowanych diod LED. Ostatnim elementem układu jest przekaźnik, który otwiera lub zamyka element końcowy jakim jest brama wjazdowa lub szlaban.

\section{Komponenty sprzętowe}

Urządzenie Raspberry Pi 2 jako platforma sprzętowa, posiada własne komponenty takie jak karta sieciowa lub port obsługi kart micro SD. Zapewnia również możliwość rozszerzenia funkcjonalności o kolejne podzespoły dzięki wbudowanym portom.

\subsection{Schemat podłączenia}

Zewnętrzne komponenty zostały podłączone do urządzenia Raspberry Pi 2 bezpośrednio za pomocą portów wejścia/wyjścia GPIO (General Purpose Input/Output). Rysunek 1 przedstawia wykorzystanie portów wejścia oraz wyjścia. Na schemacie nie uwzględniono rezystorów zabezpieczających Raspberry Pi 2 przed przeciążeniem.

Do urządzenia podłączono następujące komponenty:

- kamerę,

- czujnik zbliżeniowy,

- 3 diody sygnalizacyjne,

- 2 diody oświetlające otoczenie,

- przekaźnik.

Czujnik zbliżeniowy odpowiada za detekcję pojazdu przed bramą wjazdową. Kamera tworzy obraz tablicy rejestracyjnej, po czym przekazuje go do analizy. Trzy diody sygnalizacyjne informują o stanie urządzenia. Dwie diody doświetlające służą do oświetlenia analizowanej tablicy w nocy. Przekaźnik jest końcowym efektem wykonawczym otwierającym bramę wjazdową. 


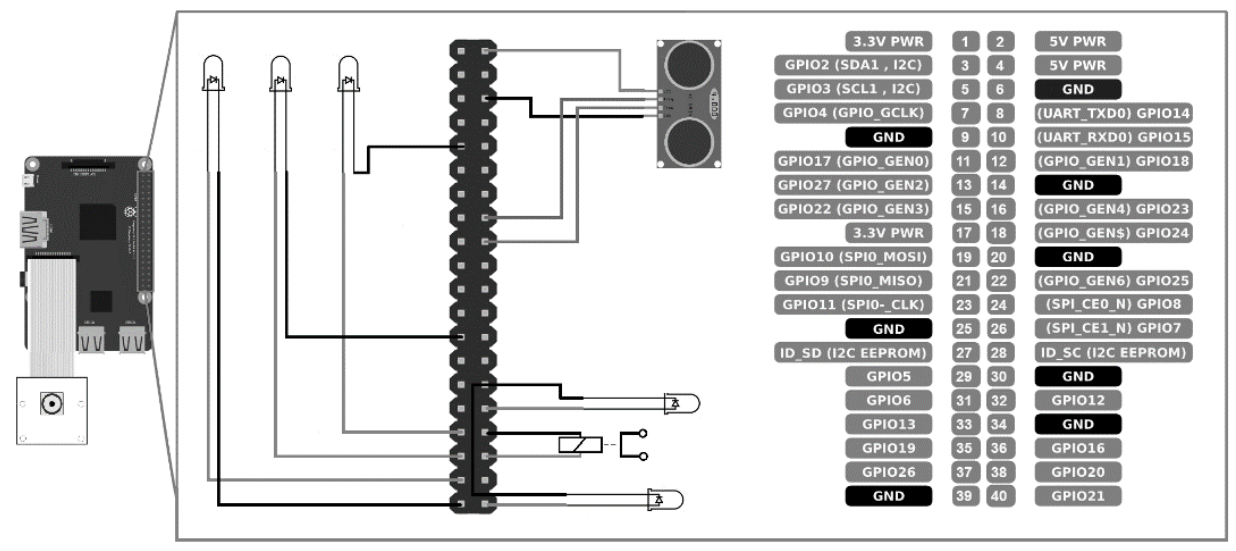

Rys. 1.Schemat podłączenia poszczególnych komponentów

Fig. 1. Diagram presenting connections between components

\subsection{Kamera}

Kamera wykorzystywana w prototypowym rozwiązaniu jest pierwszą wersją przeznaczoną dla urządzenia Raspberry Pi. Do urządzenia podłączona jest za pomocą dedykowanego portu. Kamera ma niewielkie rozmiary $(25 \times 24 \times 9 \mathrm{~mm})$ i waży zaledwie $3 \mathrm{~g}$. Matryca do przetwarzania obrazu jest wyposażona w sensor OmniVision OV5647 o rozdzielczości 5 MPx. Maksymalna rozdzielczość, z jaką można zrobić zdjęcie, to $2592 \times 1944$ pikseli. Dzięki sprzętowemu wsparciu formatu h.264, możliwe jest także nagrywanie filmów w następujących rozdzielczościach:

- Full HD1080, przy zachowaniu 30 klatek na sekundę,

- HD720 przy 60 klatkach na sekundę,

- SD 640×480 przy maksymalnej prędkości 90 klatek na sekundę [3].

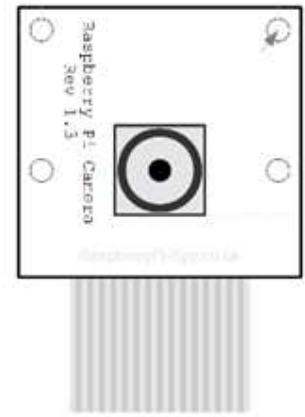

Rys. 2. Schemat kamery [2]

Fig. 2. Scheme of the camera [2] 


\subsection{Czujnik HC-04}

Do odczytu odległości zastosowano czujnik ultradźwiękowy HC-SR04. Czujnik charakteryzuje się wysoką dokładnością $(0,3 \mathrm{~cm})$ oraz szerokim 30 stopniowym kątem pracy. Odległość mierzona mieści się w przedziale od $2 \mathrm{~cm}$ do $400 \mathrm{~cm}$. Poza tym przedziałem urządzenie również odczytuje odległość, jednak pomiar jest niedokładny i podatny na zakłócenia. Czujnik jest zasilany napięciem 5V, pochodzącym bezpośrednio z Raspberry Pi 2. Odległość od przeszkody jest mierzona na podstawie prędkości dźwięku oraz czasu w jakim dana fala akustyczna zostanie wysłana z czujnika oraz do niego wróci. Obszar pracy przedstawia rys. 3 [4].

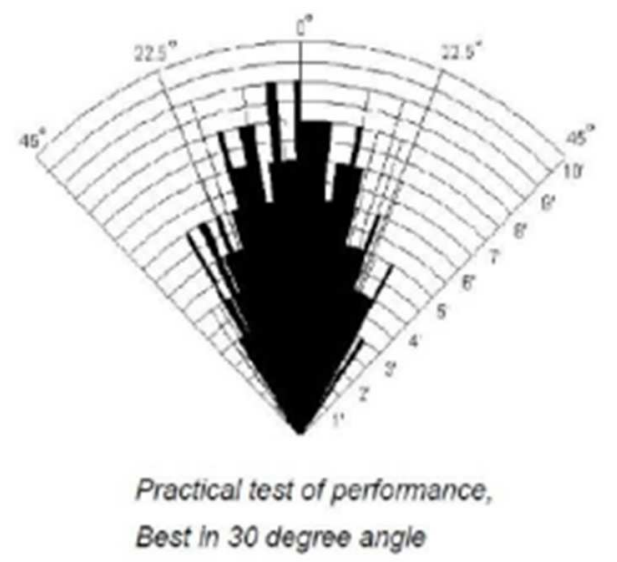

Rys. 3. Obszar pracy czujnika [4]

Fig. 3. Work area of the sensor [4]

\section{Struktura programowa}

Urządzenie do zarządzania danymi posługuje się zaimplementowaną usługą sieciową (z ang. web service). Za jej pośrednictwem możliwe jest odczytywanie informacji o tablicach rejestracyjnych oraz dodawanie nowych tablic lub ich usuwanie. WebSerwis jest obsługiwany przez proces uruchamiany podczas startu urządzenia. Proces posiada bezpośredni dostęp do bazy danych, w której zapisuje dane lub je odczytuje. Usługa sieciowa wykorzystuje format $X M L$ (z ang. Extensible Markup Language). Zastosowaną bazą danych jest PostgreSQL [5].

Do zadań procesu uruchamianego podczas startu urządzenia należy również detekcja obrazu oraz sterowanie wszystkimi portami wejścia/wyjścia. Zarządza on pracą aparatu oraz czujnika zbliżeniowego. Przepływ danych w projekcie prezentuje rys. 4. 


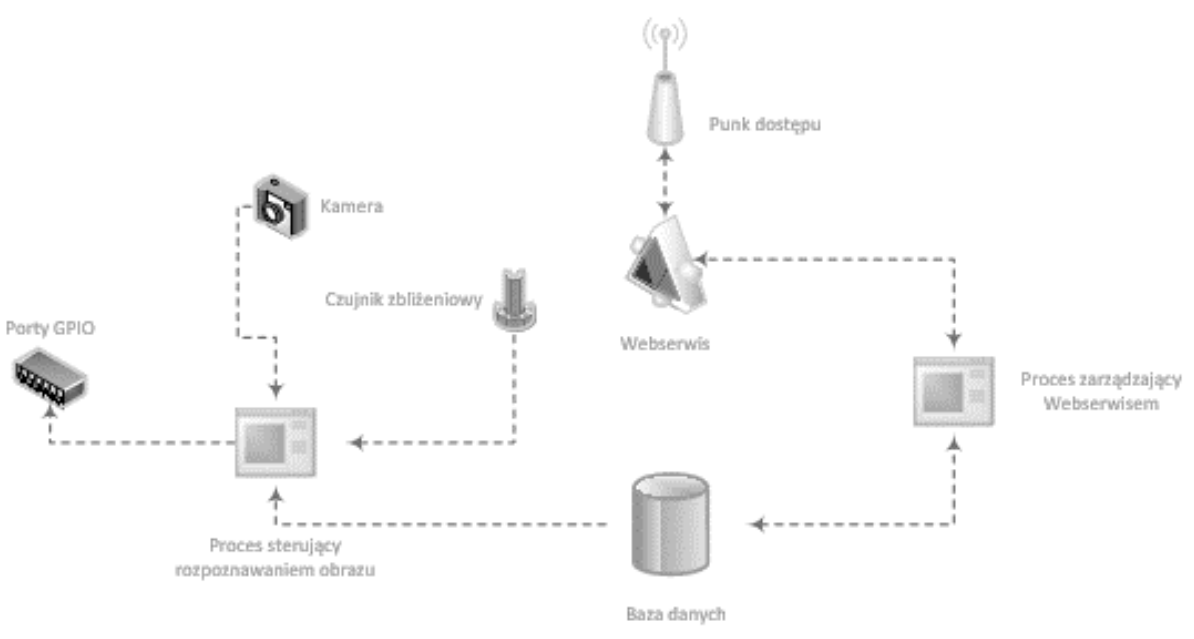

Rys. 4. Schemat przepływu informacji.

Fig. 4. Model of information flow.

\section{Algorytm}

Proces główny rozpoznaje tablice poprzez wykonanie szeregu kroków, przedstawionych na Rys. 5.

Pierwszym krokiem jest wczytanie konfiguracji, w tym ustawień diod kontrolnych, portów oraz wczytanie zakresu odległości. Operacje te wykonywane są podczas startu procesu. Urządzenie zgłasza gotowość poprzez zaświecenie diody LED1.

Następnie urządzenie odczytuje odległość z czujnika zbliżeniowego i sprawdza, czy pojazd znajduje się w odpowiednim miejscu. Przedział jest definiowany przez odległość minimalną i odległość maksymalną. Jeżeli w odpowiednim miejscu od czujnika znajduje się samochód, zostaje zaświecona dioda LED2. Aplikacja czeka 4 sekundy w celu stwierdzenia, czy samochód dalej znajduje się przed urządzeniem. Jeżeli nie, to następuje powrót do pierwszej detekcji odległości.

Jeżeli wykryto samochód, to ponownie odczytywany jest dystans do niego. Jeżeli odległość się zmieniła, to należy wrócić do pierwszego pomiaru, ponieważ zachodzi obawa, że mieliśmy do czynienia z zakłóceniem jakim może być np. przypadkowy pieszy. Jeżeli odległość nie uległa zmianie, to następuje przejście do kolejnego etapu polegającego na utworzeniu obrazu.

W etapie tworzenia obrazu dioda LED2 zaczyna mrugać, a także zostają włączone diody doświetlające. Zostaje wykonane zdjęcie oraz realizowana jest analiza obrazu. Odczytany tekst zostaje przekazany do bazy w celu stwierdzenia, czy numer tablicy rejestracyjnej znajduje się na liście pojazdów z przydzie- 
lonym dostępem. Jeżeli w bazie nie ma takiej rejestracji lub rejestracja jest nierozpoznana to należy przejść do drugiego pomiaru, czyli do ponownej próby odczytania tablicy. Gdy rejestracja została rozpoznana, następuje otwarcie bramy poprzez odblokowanie przekaźnika, a diody doświetlające zostają zgaszone.

Kolejne czynności mają na celu upewnienie się, że nie nastąpi zamknięcie bramy, zanim samochód nie przemieścił się poza region, w którym mógłby ulec uszkodzeniu przy próbie zamknięcia bramy. W tym celu czujnik mierzy ponownie odległość aby sprawdzić obecności samochodu. Jeżeli jest obecny, to urządzenie czeka 2 sekundy, po czym ponownie sprawdza obecność. Operacja jest wykonywana do momentu stwierdzenia, że samochodu już nie ma. Gdy ten odjechał, następuje zamknięcie bramy.

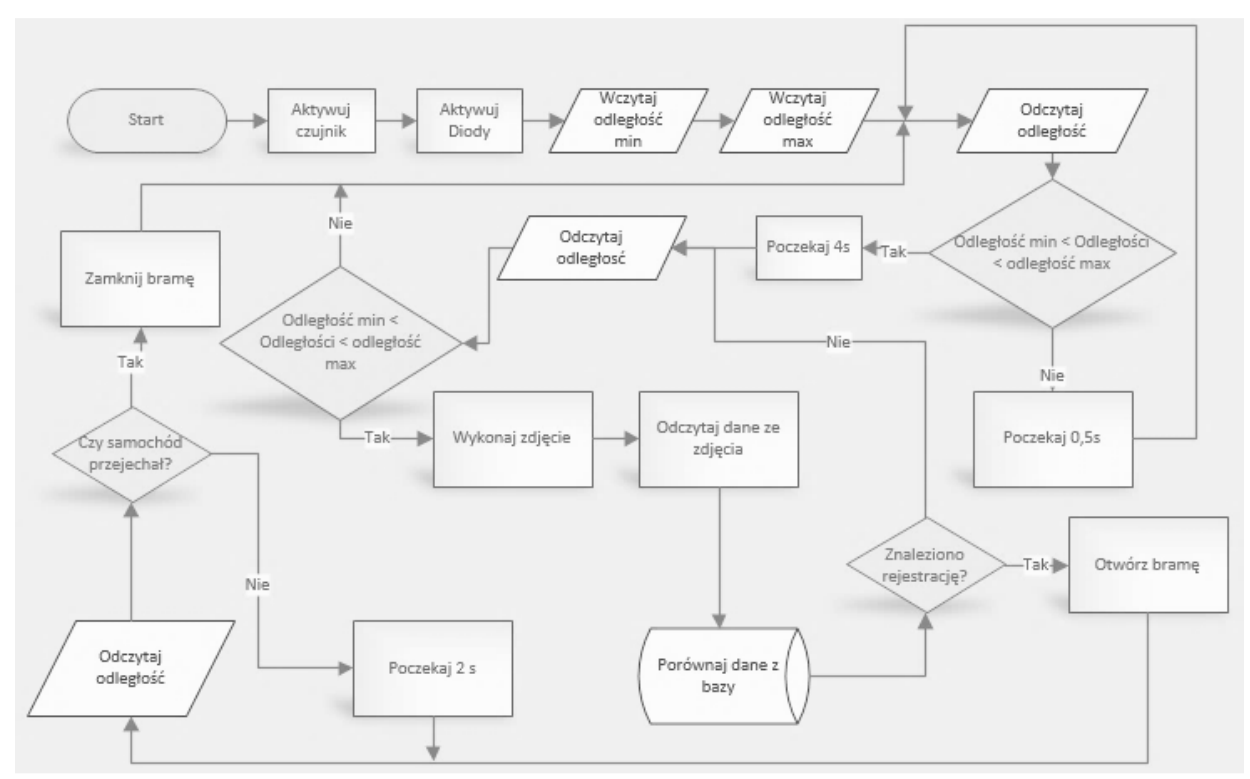

Rys. 5. Algorytm działania systemu

Fig. 5. Algorithm of the system

\section{Rozpoznawanie tekstu}

Rozpoznawanie tekstu $\mathrm{z}$ obrazu jest procesem dość skomplikowanym a przy nieodpowiednio przygotowanym obrazie, bardzo wymagającym obliczeniowo [6,7]. Obecnie do tego celu wykorzystuje się sieci neuronowe, które skutecznie są w stanie rozpoznać badany tekst $[8,9]$. Poprawność jest uzależniona od wielu czynników, takich jak wielkość tekstu czy jakość zdjęcia. Jednak aby algorytmy szybko działały niezbędne jest wcześniejsze przygotowanie 
obrazu w celu zminimalizowania zakłóceń. Rozpoznawanie tekstu w opisywanym projekcie zostało podzielne na dwie części, omówione poniżej.

W pierwszej części obraz jest poddany obróbce w celu wyeliminowania zakłóceń, detali oraz innych zbędnych elementów. W tym celu wykorzystano bibliotekę OpenCV [10,11,12], która jest bogatym zbiorem funkcji do szybkiego przetwarzania obrazów. Biblioteka posiada otwarty kod źródłowy (Open Source). Oprócz funkcji do obróbki obrazów 2D i 3D, zawiera funkcje wykrywające gesty oraz ruch. Może być także używana w czasie rzeczywistym.

Obróbkę przykładowego zdjęcia, w kontekście prototypowego systemu rozpoznawania tablic rejestracyjnych, przedstawiają rysunki 6-9.

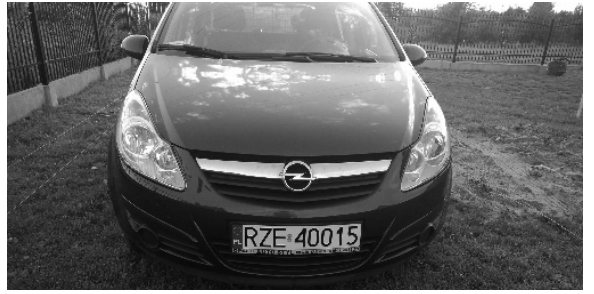

Rys. 6. Obraz w skali szarości

Fig. 6. Image in grayscale

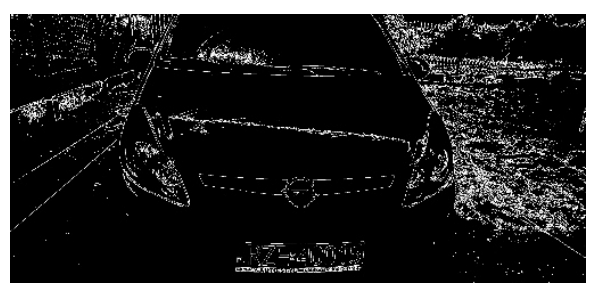

Rys. 8. Kontury obrazu

Fig. 8. Contour of image

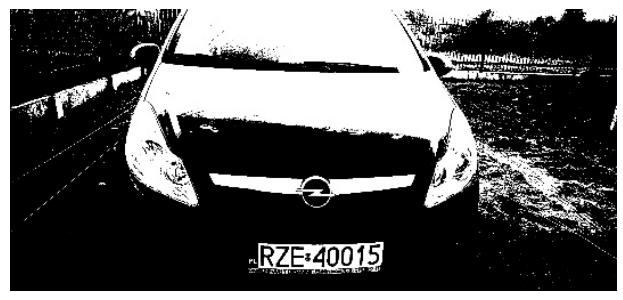

Rys. 7. Obraz zbinaryzowany

Fig. 7. Binary image

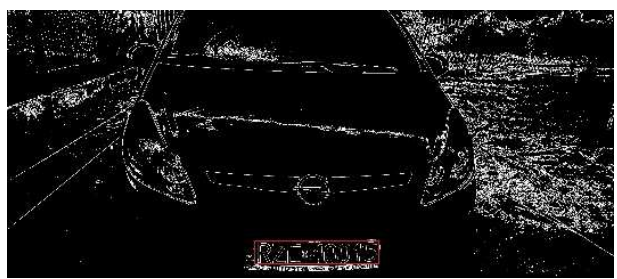

Rys. 9. Wykryty tekst

Fig. 9. Detected text

Proces detekcji obrazu można opisać w czterech krokach.

1. Pierwszym krokiem jest zmniejszenie wielkości zdjęcia. Obraz składa się z pikseli, a każdy piksel jest opisany trzema kolorami RGB (Red Green Blue). Rozmiar obrazu to iloczyn wysokości w pikselach, szerokość w pikselach oraz koloru w bitach. Kolor zazwyczaj jest opisany 24 bitami. Taki iloczyn daje wielkość obrazu w bitach. Jeżeli natomiast skonwertujemy obraz jako odcienie szarości, to kolor 1 piksela będzie opisywać jedynie 8 bitów, przez co wielkość zmniejszy się 16-krotnie (Rys.6). 
2. Drugi krok powoduje binaryzację czyli przedstawienie obrazu w dwóch kolorach: czarnym i białym. W tym kroku również maleje wielkość ponieważ kolor opisuje 1 bit (Rys.7).

3. Trzecim krokiem jest zastosowanie funkcji Contur. Dzięki niej możliwe jest wyodrębnienie kontur z przetwarzanego obrazu (Rys. 8).

4. Ostatnim krokiem jest wyodrębnienie $\mathrm{z}$ obrazu możliwej tablicy rejestracyjnej (Rys. 9).

Druga cześć odpowiada za rozpoznanie wykrytego obrazu. W tym celu wykorzystano bibliotekę Tesseract OCR [13]. Zawiera ona zestaw funkcji służących do rozpoznawania znaków i całych bloków tekstów w pliku graficznym. Cały mechanizm opiera się na działaniu sieci neuronowej. Na początku klasyfikator sieci poddawany jest treningowi. Trenowanie (uczenie sieci) odbywa się podczas dostarczania obrazów prawidłowych znaków. Po tym procesie sieć zna kształty liter oraz jest w stanie rozpoznać nowe obrazy. Proces ten nie daje jednak 100\% skuteczności i występują obrazy, które zostają rozpoznane błędnie.

\section{Badania i testy}

System rozpoznawania tablic przetestowano pod kątem powtarzalności oraz poprawności rozpoznawania obrazów. Do testów wykorzystano zdjęcia 20 tablic zrobione w różnych warunkach atmosferycznych. Zbadano również wpływ odległości od urządzenia.

W pierwszym teście przeprowadzono analizę odczytu biorąc pod uwagę odległość do fotografowanej tablicy. Zmiana odległości przekłada się na zmianę wielkości czcionki. Na Rys. 10. można zaobserwować, że wraz ze wzrostem wielkości wzrasta poprawność dopasowania. Proces ten jest prawie liniowy do momentu osiągnięcia wielkości 44 pikseli.

$\mathrm{W}$ tym momencie algorytm przestaje działać poprawnie, ponieważ $\mathrm{w}$ badanym przypadku tablica rejestracyjna jest umieszczona w plastikowej ramce, na której jest tekst reklamowy. Powoduje to problem w działaniu algorytmu. Tekst o rozmiarze powyżej 49 pikseli jest rozpoznawany prawidłowo aż do 74 pikseli gdzie również nie jest możliwe rozpoznanie.

Drugi test przedstawia symulację zanieczyszczeń obrazu (Rys. 11) wykonaną poprzez nałożenie zakłóceń na obraz. Widać wyraźnie, że im większa skala zakłócenia, tym mniejsza poprawność rozpoznawania tekstu. Przy zastosowaniu zanieczyszczenia obrazu rzędu $25 \%$, tablica rejestracyjna nie zostanie już odczytana. 


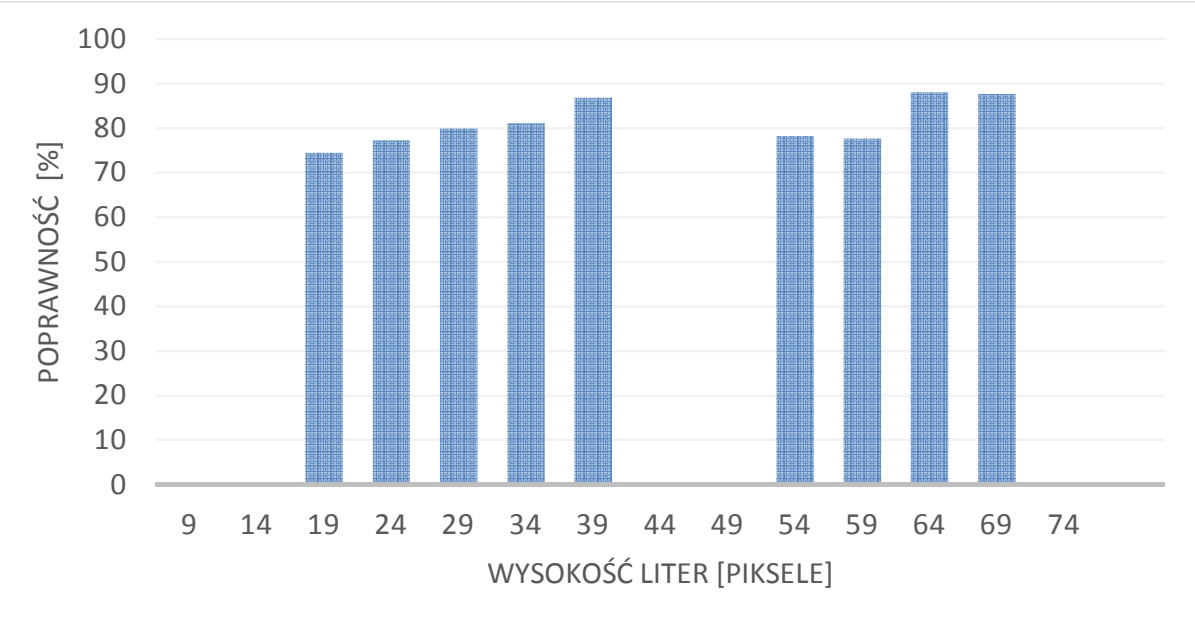

Rys. 10. Badanie poprawności odczytu tablic w zależności od wielkości tekstu

Fig. 10. Correctness of reading license plates depending on the size of the text

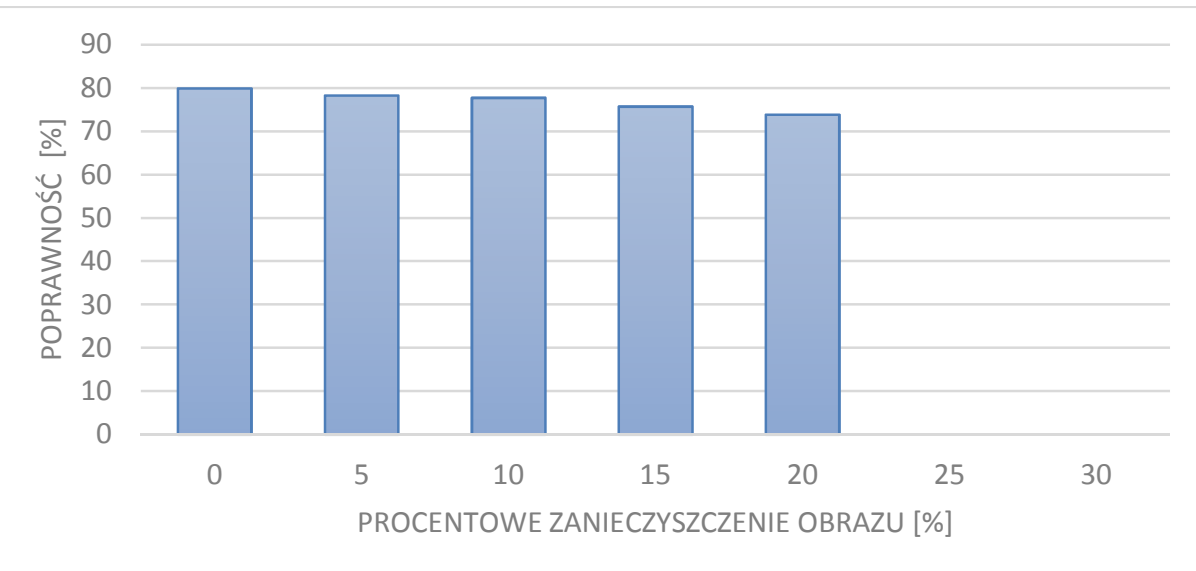

Rys. 11. Badanie poprawności odczytu tablic w zależności od zanieczyszczeń.

Fig. 11. Correctness of reading license plates depending on contamination

\section{Podsumowanie}

Urządzenie Raspberry Pi 2, jako platforma sprzętowa nadaje się do operacji związanych z przetwarzaniem obrazu. Zastosowanie komponentów sprzętowych, takich jak czujnik zbliżeniowy, pozwala zwiększyć wydajność i skuteczność systemu. Zastosowanie bezprzewodowej karty sieciowej pozwoliło na zdalne zarządzanie urządzeniem, zaś diody LED w łatwy sposób informują o aktualnym stanie systemu. Dodatkowe diody umożliwiają odczytywanie nu- 
merów rejestracyjnych w nocy. Dzięki systemowi Linux oraz utworzonej aplikacji, urządzenie stało się niezależną jednostką obliczeniową, która do prawidłowej pracy potrzebuje jedynie zasilania.

Zastosowanie sieci neuronowej do rozpoznawania tablic rejestracyjnych pokazało, że ten sposób rozpoznawania obrazu w znacznym stopniu poprawia wydajność oraz poprawność odczytywanego tekstu. Specjalnie zaprojektowany algorytm pozwala na detekcję niechcianych obiektów oraz umożliwia rozpoznawanie numerów tablic rejestracyjnych w celu zarządzania dostępem.

Przeprowadzone testy dowiodły, że odległość od mierzonego obiektu ma znaczenie. Nie jest to jednak zależność liniowa. Test pokazał również, że istnieje wielkość liter dla której odczyt jest niemożliwy. Wprowadzenie zanieczyszczenia do badanej rejestracji powoduje zmniejszenie poprawności odczytu. Nie powoduje jednak zakłóceń w samym procesie odczytu. Odczyt jest poprawny do pewnego progu występowania zakłócenia. Po przekroczeniu niego, odczyt jest już niemożliwy.

W kolejnym etapie prac należałoby zastosować kamerę na podczerwień w celu poprawy jakości zdjęć nocnych. Pozwoli to zrezygnować z zastosowanych diod do oświetlenia $\mathrm{w}$ nocy oraz przyśpieszy działanie całego procesu ponieważ obraz odczytany $\mathrm{z}$ kamery podczerwonej automatycznie jest jak w skali szarości.

\section{Bibliografia}

[1] Upton E.: Raspberry Pi User Guide Wiley 2013.

[2] http://www.raspberrypi-spy.co.uk/wp-content/uploads/2013/05/Raspberry-PiCamera-Module-Diagram.png

[3] https://www.raspberrypi.org/documentation/hardware/camera/README.md

[4] https://docs.google.com/document/d/1Y-yZnNhMYy7rwhAgyL_pfa39RsB$\mathrm{x} 2 \mathrm{qR} 4 \mathrm{vP} 8 \mathrm{saG} 73 \mathrm{rE} / \mathrm{edit}$

[5] http://www.postgresql.org.pl/

[6] Tadeusiewicz R.: Sieci neuronowe, Akademicka Oficyna Wydawnicza, Warszawa 1993.

[7] Clarke A.: OCR Functional Skills, Hodder \& Stoughton, 2010.

[8] http://www.ftj.agh.edu.pl/ stegowski/rozne/neurony/art_kern_1.pdf

[9] Michalewicz Z.: Algorytmy genetyczne + struktury danych = programy ewolucyjne, Wydawnictwo WNT, 2003.

[10] Bradski G., Kaehler A.: Learning OpenCV Computer Vision with the OpenCV Library, Publisher: O'Reilly Media, Final Release Date: September 2008, Pages: 580 .

[11] Mori S., Nishida H., Yamada H.: Optical Character Recognition, Authors: Publication: Cover Image Book Optical Character Recognition, $1^{\text {st }}$ John Wiley \& Sons, Inc. New York, USA, 1999, ISBN 0471308196.

[12] http://opencv.org/

[13] https://github.com/tesseract-ocr/tesseract/wiki 


\section{PROTOTYPE SYSTEM OF RECOGNIZING NUMBER PLATES WITH USING ARTIFICIAL NEURAL NETWORKS}

\section{S u m m a r y}

The article has been presented prototype system of recognizing a number of plates based on Raspberry Pi 2. The system was designed as the low-budget alternative to dear commercial solutions. This article is describing individual equipment components, the application controlling, the recognition process of the text and conducted examinations, showing the correctness of the reading. An applied algorithm has been described, as well as recognizing the text based on artificial neural networks.

Keywords: OCR, OpenCV, Python, Raspberry PI 2

DOI: $10.7862 /$ re.2017.9

Tekst złożono w redakcji: wrzesień 2017

Przyjęto do druku: październik 2017 
